\title{
Examination of Cognitive Flexibility and Social Appearance Anxiety Levels of Physical Education and Primary School Teachers
}

\section{Metin KARAYOL ${ }^{\circledR}$ Yahya DOĞAR ${ }^{2}$}

'School of Physical Education and Sports, Mussilparslan University, Turkey. Email:m.karavol@alparslan.edu.tr

${ }^{2}$ Faculty of Sports Sciences, İnönü University, Turkey.

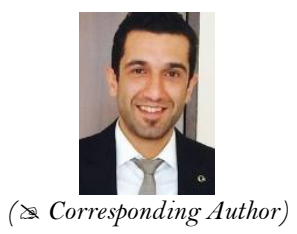

\begin{abstract}
The aim of this research study is to examine the cognitive flexibility and social appearance anxiety levels of physical education and sports teachers and primary school teachers. The study group consists of 160 participant (56 famele, 104 male) in total. Personal information form created by researchers and "Cognitive Flexibility Inventory" transcribed to Turkish by Gülüm and Dağ (2012) and "Social Appearance Anxiety Scale, transcribed to Turkish by Doğan (2010) has been used as a data collector in the study. In the analysis of data, the T-test has been used in the comparison of quantitative continuous data between two independent groups and the One Way Anova test has been used in the comparison of quantitative continuous data between more than two independent groups. Scheffe test has been used as the completive post hoc analysis to determine the differences after the Anova test. Pearson correlation analysis was implemented among the continuous variables of the study. As a result of the study, there was a statistically significant difference between the levels of cognitive flexibility and ability to produce alternative solutions as well as between the cognitive flexibility overall scores and teaching experience $(\mathrm{p}<0.05)$. It was determined that there were statistically significant differences among the social appearance anxiety scores concerning gender, school, and teaching branch variables $(\mathrm{p}<0.05)$. It was determined that there was statistically no significant relationship between cognitive flexibility overall scores and social appearance anxiety levels $(\mathrm{p}>0.05)$.
\end{abstract}

Keywords: Sports management, Physical education, Cognitive flexibility, Social appearance anxiety.

Citation | Metin KARAYOL; Yahya DOĞAR (2020). Examination of Cognitive Flexibility and Social Appearance Anxiety Levels of Physical Education and Primary School Teachers. Asian Journal of Education and Training, 6(2): 176-180.

\section{History:}

Received: 18 December 2019

Revised: 30 January 2020

Accepted: 5 March 2020

Published: 27 March 2020

Licensed: This work is licensed under a Creative Commons

Attribution 3.0 License (oc) E

Publisher: Asian Online Journal Publishing Group
Acknowledgement: Both authors contributed to the conception and design of the study.

Funding: This study received no specific financial support

Competing Interests: The authors declare that they have no conflict of interests.

Transparency: The authors confirm that the manuscript is an honest, accurate, and transparent account of the study was reported; that no vital features of the study have been omitted; and that any discrepancies from the study as planned have been explained.

Ethical: This study follows all ethical practices during writing.

\section{Contents}

1. Introduction ...u.

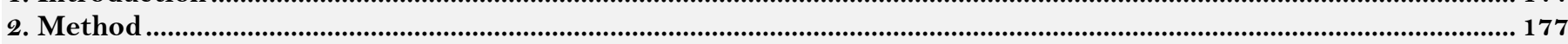

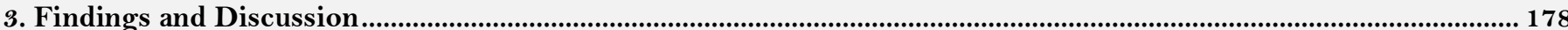

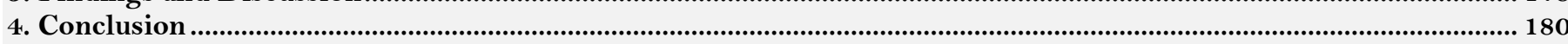

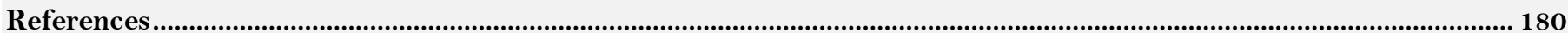




\section{Contribution of this paper to the literature}

This study contributes to the existing literature by examining the cognitive flexibility and social appearance anxiety levels of physical education and sports teachers and primary school teachers.

\section{Introduction}

Sport is a whole of physical activities that aim at solidarity and cohesion in order for individuals to be physically, spiritually, and mentally healthy and well in the life (Eroğlu, 2019; Eroğlu. \& Ersoy, 2019; T. Murathan, 2018). It is also known that there are many accepted benefits of physical education and sports in the literature. Thanks to society's perception of sports, these benefits are not only in psychological and sociological aspects but also in physical, physiological, and spiritual terms (Aygun, 2019; Eroğlu, 2019). On the other hand, learning and teaching activities are a long process that starts with the onset of the life of individuals on Earth and ends with the end of their life in the universe (Talha Murathan \& Özdemir, 2017). In this context, there are many factors that affect the psychological, spiritual, and mental states of individuals; additionally, cognitive flexibility perspectives and social appearance concerns are among the issues that should be addressed especially for our teachers who are part of our education.

Cognitive flexibility is defined as the skill for balancing situations, decision-making and considering many options while making these decisions, addressing events from different perspectives in a crisis, empathy, taking into consideration the facts and knowledge when considering the cause of any behavior, producing efficient solutions in the face of difficult situations, and managing the cases of losing control. In another definition, cognitive flexibility can also be defined as the ability of an individual to change the way he/she looks at a task or the way he/she thinks. Individuals with high cognitive flexibility can make easy and spontaneous changes, while individuals with low cognitive flexibility have difficulty in making changes (Cox, 1980). Individuals with cognitive flexibility reduce the negative behaviors and expand the tolerance limits. In individuals, who don't have this flexibility, the number of mistakes continuously increases and it becomes inevitable for them to have difficulties in the face of any crisis. It is considered vital for today's physical education and sports teachers and primary school teachers to have cognitive flexibility not only for the future of their students but also for the efficiency of the education they receive. Hart, Leary, and Rejeski (1989) described social appearance anxiety as a subtype of social anxiety that occurs as a result of the presence of interpersonal evaluations considering the appearance or the possibility of such an assessment. According to another definition, social anxiety, known as social phobia, is defined as a disorder that causes avoidance from social situations that starts mostly during the adolescence with the fear of being evaluated by other people in relatively small groups. Hart et al. (1989) addressed social appearance anxiety as the concerns involving other people's assessments of one's physical appearance. In more specific terms, social appearance anxiety is also referred to as the type of social anxiety that involves the anxiety of being evaluated by other people regarding external appearance. Some people assume that others like their physical appearance, or ignore the thoughts of others about their physical appearance, and therefore, they partially experience social appearance anxiety (Hart et al., 1989). Based on the definitions of the concepts, we think that the concepts of cognitive flexibility and social appearance anxiety are intertwined. A qualified physical education teacher should have a good appearance besides many features (Uğraş \& Güllü, 2019). Therefore, in order for the physical education and sports teachers and primary school teachers to overcome the problems they will encounter while performing their profession and in terms of their task definitions, reducing their appearance anxiety will contribute to their students. Accordingly, in the study, it was aimed to examine the cognitive flexibility and social appearance anxiety levels of physical education and sports teachers and primary school teachers working in Provincial Directorate of National Education of Muş.

\section{Method}

The sample group of this study was composed of 160 physical education and sports teachers (101) and primary school teachers (59) working under the Provincial Directorate of National Education of Muş. In the materials and methods section, demographic characteristics of participants, study variables, data collection tools, and statistical methods applied to the data were discussed.

\subsection{Model of Research}

In this study, a general survey model, one of the descriptive research methods, was applied. The general survey model was described in Karasar (2005) as a research method that aims to define an existing situation as is.

\subsection{Data Collection Tools}

Cognitive Flexibility Inventory (CFI): In order to determine the flexibility level, the 20-item scale, which was developed by Dennis and Wal (2010) was used in the research. The scale includes alternative thinking skills, coherent and balanced thinking statements in the face of difficult situations. The statements of the scale are divided into two sub-dimensions as the Ability to Produce Alternative Solutions (1, 3, 5, 6, 8, 10, 12, 13, 14, 16, 18, 19, 20) and the Tendency to Control $(2,4,7,9,11,15,17)$. The adaptation of the scale to Turkish culture was conducted by Gülüm and Dă̆ (2012). Gülüm and Dă̆ found the internal consistency coefficient, Cronbach's Alpha as 0.900. In this study, the reliability of the cognitive flexibility scale was determined as high, since the Cronbach's Alpha was 0.742 .

Social Appearance Anxiety Scale (SAAS): Turkish adaptation of the scale, which was developed by Hart. et al. (2008) in order to measure the social appearance anxiety levels of individuals, was conducted by Doğan (2010). This 5-point Likert scale consists of 16 items. The lowest possible score is 16 and the highest possible score is 80 in this one-dimensional scale. High scores indicate that the social appearance anxiety level is high. The reliability of the social appearance anxiety scale was determined as high in this study, since the Cronbach's Alpha was 0.958. 


\subsection{Data Analysis}

The data obtained from the study were analyzed using the SPSS (Statistical Package for Social Sciences) for Windows 22.0. In the evaluation of the data, number, percentage, mean, and standard deviation were used as the descriptive statistical methods. The t-test was used to compare quantitative continuous data between two independent groups, and the one-way ANOVA test was used to compare quantitative continuous data between more than two independent groups. The Scheffe test was used as a complementary post-hoc analysis to determine the differences after the ANOVA test. Pearson correlation analysis was applied among the continuous variables of the study.

\section{Findings and Discussion}

This section contains the findings as a result of the analysis of the data collected from the participant teachers through the scales to solve the research problem. Explanations and interpretations were made depending on the findings.

Table-1. Demographic characteristics distribution table.

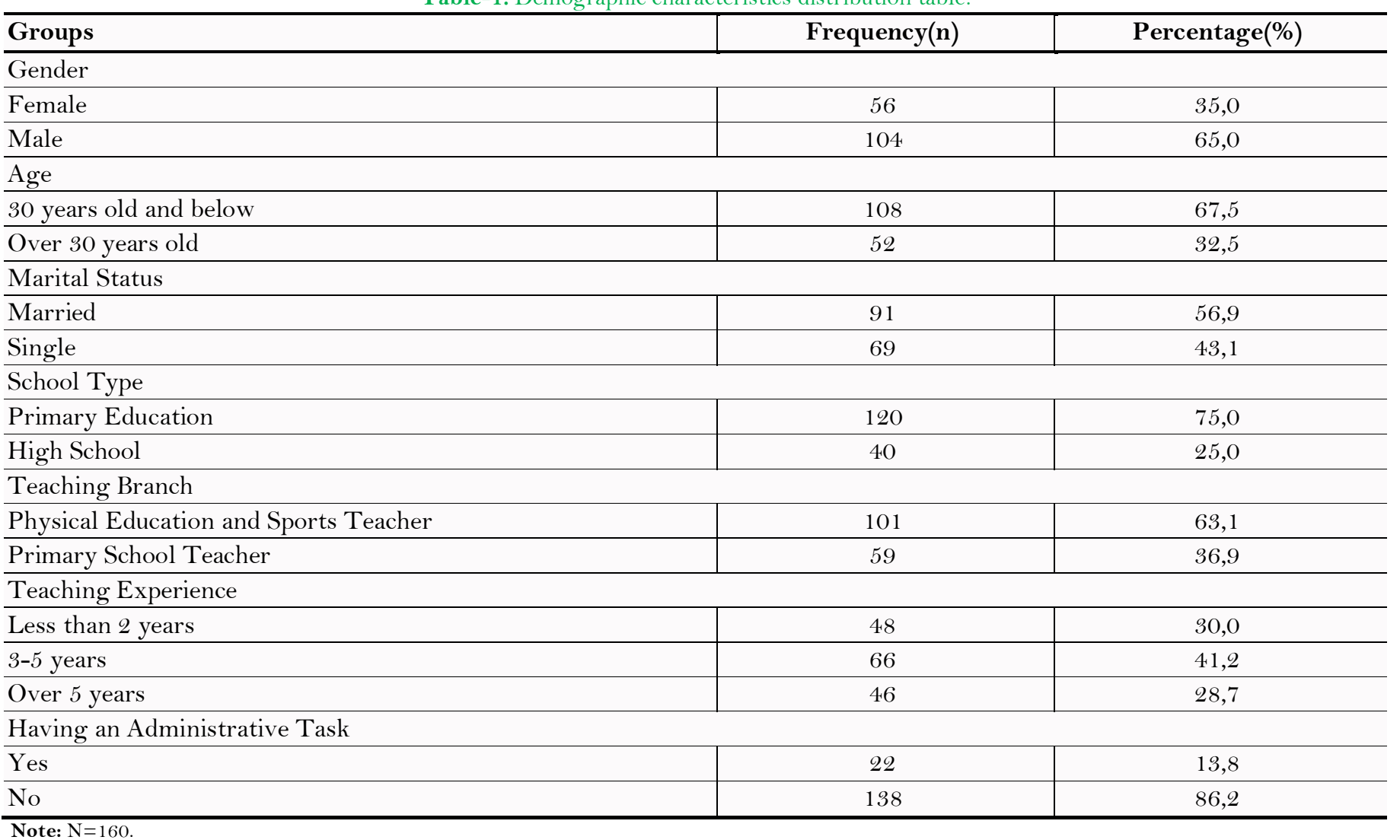

Table 1 shows that it was determined that $56(35.0 \%)$ of the teachers were female and $104(65.0 \%)$ were male; $108(67.5 \%)$ of them were 30 years old and below, $52(32.5 \%)$ were over 30 years old; $91(56.9 \%)$ were married and $69(43.1 \%)$ were single; $120(75.0 \%)$ of them were working in primary schools and $40(25.0 \%)$ were in high schools; $101(63.1 \%)$ were physical education and sports teachers and $59(36.9 \%)$ were primary school teachers; $48(30.0 \%)$ had a teaching experience of less than 2 years, $66(41.2 \%)$ with $3-5$ years, and $46(28.7 \%)$ had 5 years and over teaching experience; $22(13.8 \%)$ of them had an administrative task in the school, while $138(86.2 \%)$ teachers did not have any administrative tasks.

Table-2. Cognitive flexibility and social appearance anxiety mean scores.

\begin{tabular}{l|c|c|c|c|c}
\hline & N & Mean & Sd & Min. & Max. \\
\hline Ability to Produce Alternative Solutions & 160 & 3,714 & 0,388 & 2,920 & 5,000 \\
\hline Tendency to Control & 160 & 3,861 & 0,417 & 2,860 & 5,000 \\
\hline Overall Cognitive Flexibility & 160 & 3,766 & 0,378 & 3,000 & 5,000 \\
\hline Social Appearance Anxiety & 160 & 30,763 & 14,149 & 16,000 & 80,000 \\
\hline Note: Min/Max.
\end{tabular}

Note: Min/Max.

Table 2 reported that their mean score concerning the "ability to produce alternative solutions" was high with

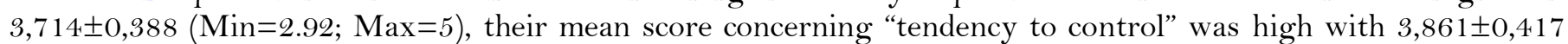
$(\mathrm{Min}=2.86$; $\mathrm{Max}=5)$, similarly, their means score of "cognitive flexibility overall" was high with $3,766 \pm 0,378$ $(\operatorname{Min}=3$; Max=5), and the mean score of "social appearance anxiety" was determined as 30,763 $\pm 14,149$ (Min=16; $\operatorname{Max}=80)$.

Table-3. Correlation analysis between the scores of cognitive flexibility and social appearance anxiety.

\begin{tabular}{|c|c|c|c|c|}
\hline & & $\begin{array}{c}\text { Ability to Produce Alternative } \\
\text { Solutions }\end{array}$ & Tendency to Control & $\begin{array}{c}\text { Overall Cognitive } \\
\text { Flexibility }\end{array}$ \\
\hline Social Appearance Anxiety & $\mathrm{r}$ & 0,072 & 0,076 & 0,077 \\
\hline
\end{tabular}


Table 3 was determined that there was no relationship between the Overall Cognitive Flexibility and Social Appearance Anxiety ( $>>0.05)$.

Table-4. Differentiaton of the cognitive flexiblity and social appearance anxiety scores concerning the descriptive characteristics.

\begin{tabular}{|c|c|c|c|c|c|}
\hline $\begin{array}{l}\text { Demographical } \\
\text { Characteristics }\end{array}$ & $\mathbf{n}$ & $\begin{array}{c}\text { Ability to Produce } \\
\text { Alternative Solutions }\end{array}$ & $\begin{array}{l}\text { Tendency to } \\
\text { Control }\end{array}$ & $\begin{array}{c}\text { Overall Cognitive } \\
\text { Flexibility }\end{array}$ & $\begin{array}{c}\text { Social Appearance } \\
\text { Anxiety }\end{array}$ \\
\hline Female & 56 & $3,679 \pm 0,332$ & $3,832 \pm 0,381$ & $3,732 \pm 0,326$ & $25,839 \pm 9,242$ \\
\hline$t=$ & & $-0,858$ & $-0,645$ & $-0,822$ & $-3,331$ \\
\hline $\mathrm{p}=$ & & 0,361 & 0,520 & 0,412 & 0,000 \\
\hline Age & & Mean \pm SD & Mean \pm SD & Mean \pm SD & Mean \pm SD \\
\hline$t=$ & & $-0,805$ & $-1,726$ & $-1,203$ & $-0,815$ \\
\hline $\mathrm{p}=$ & & 0,422 & 0,086 & 0,231 & 0,417 \\
\hline Marital Status & & Mean $\pm \mathrm{SD}$ & Mean $\pm \mathrm{SD}$ & Mean $\pm \mathrm{SD}$ & Mean $\pm \mathrm{SD}$ \\
\hline Married & 91 & $3,747 \pm 0,383$ & $3,903 \pm 0,424$ & $3,802 \pm 0,373$ & $30,308 \pm 14,416$ \\
\hline Single & 69 & $3,671 \pm 0,392$ & $3,805 \pm 0,406$ & $3,718 \pm 0,381$ & $31,362 \pm 13,870$ \\
\hline $\mathrm{t}=$ & & 1,232 & 1,465 & 1,390 & $-0,466$ \\
\hline $\mathrm{t}=$ & & 0,271 & $-0,311$ & 0,060 & $-3,607$ \\
\hline $\mathrm{p}=$ & & 0,822 & 0,784 & 0,960 & 0,006 \\
\hline Teaching Branch & & Mean \pm SD & Mean \pm SD & Mean \pm SD & Mean \pm SD \\
\hline $\begin{array}{l}\text { Physical Education and } \\
\text { Sports Teacher }\end{array}$ & 101 & $3,724 \pm 0,436$ & $3,856 \pm 0,468$ & $3,770 \pm 0,426$ & $33,792 \pm 16,153$ \\
\hline Primary School Teacher & 59 & $3,698 \pm 0,288$ & $3,869 \pm 0,315$ & $3,758 \pm 0,279$ & $25,576 \pm 7,456$ \\
\hline$t=$ & & 0,420 & $-0,197$ & 0,204 & 3,681 \\
\hline $\mathrm{p}=$ & & 0,642 & 0,828 & 0,821 & 0,000 \\
\hline Teaching Experience & & Mean \pm SD & Mean \pm SD & Mean \pm SD & Mean \pm SD \\
\hline Less than 2 years & 48 & $3,588 \pm 0,395$ & $3,750 \pm 0,414$ & $3,645 \pm 0,380$ & $34,292 \pm 16,262$ \\
\hline $3-5$ years & 66 & $3,739 \pm 0,398$ & $3,877 \pm 0,457$ & $3,787 \pm 0,399$ & $28,939 \pm 10,772$ \\
\hline 5 years and over & 46 & $3,811 \pm 0,334$ & $3,953 \pm 0,335$ & $3,861 \pm 0,313$ & $29,696 \pm 15,626$ \\
\hline $\mathrm{p}=$ & & 0,348 & 0,171 & 0,248 & 0,082 \\
\hline
\end{tabular}

Note: $* 0,05 ; * * * 0,01$

Table 4 was determined that the social appearance anxiety scores of women $(x=25,839)$ were lower compared to the social appearance anxiety scores of men $(\mathrm{x}=33,414)(\mathrm{t}=3-331 ; \mathrm{p}=0<0.05)$. It was found that there was statistically no significant difference concerning ability to produce alternative solutions, tendency to control, cognitive flexibility overall scores of teachers in terms of gender variable $(p>0.05)$. Similar to the findings of our study, in a study conducted by Alemdağ and Oncü (2015) it was determined that there were statistically significant differences between social appearance anxiety scores and gender among teacher candidates. The social appearance anxiety scores of the males were found to be higher compared to those of the women. A study conducted by Doğan (2010) indicated that males have higher social anxiety levels compared to the females. In a study conducted by Uzümcü and Müezzin (2018) it was determined that there were no significant differences in the cognitive flexibility levels of teachers concerning the gender. Concerning the age variable, it was determined that there was statistically no significant difference in the scores of teachers concerning the ability to produce alternative solutions, tendency to control, cognitive flexibility, and social appearance anxiety $(\mathrm{p}>0.05)$. In parallel to our study, in a study conducted on civil servants by Güzeltepe (2017) it was determined that there was statistically no significant difference among the cognitive flexibility sub-dimensions of the personnel concerning the age variable.

In terms of the marital status variable, it was determined that there was statistically no significant difference among the scores of teachers concerning the ability to produce alternative solutions, tendency to control, overall cognitive flexibility, and social appearance anxiety $(\mathrm{p}>0.05)$.

In terms of the school type variable, it was determined that the social appearance anxiety scores of the teachers working in the primary schools $(\mathrm{x}=28,517)$ were lower than those of the teachers working in high schools $(\mathrm{x}=37,500)(\mathrm{t}=-1.607 ; \mathrm{p}=0.006<0.05)$. It was determined that there was statistically no significant difference among the scores of teachers concerning the ability to produce alternative solutions, tendency to control, and overall cognitive flexibility in terms of the school type variable $(p>0.05)$. The reason that social appearance anxiety scores are high in high school teachers is that the students they teach are in their adolescence and older, and additionally, it can be considered that the constant effort of the students to follow the example of their teachers may increase the social appearance anxiety levels of their teachers. Social appearance anxiety scores of physical education and sports teachers $(\mathrm{x}=33,792)$ were higher than those of the primary school teachers $(\mathrm{x}=25,576)$ $(\mathrm{t}=3,681 ; \mathrm{p}=0<0.05)$. It was determined that there was statistically no significant difference among the scores of teachers concerning the ability to produce alternative solutions, tendency to control, and overall cognitive flexibility in terms of the teaching branch variable $(\mathrm{p}>0.05)$. In parallel with our study, a study conducted on teachers by Kılıçarslan (2006) it was determined that physical self-perceptions of physical education teachers were 
$81 \%$ positive compared to those of other branch teachers. In terms of the teaching experience variable, it was determined that there were statistically significant differences among the ability to produce alternative solutions scores of teachers $(\mathrm{F}=4,276 ; \mathrm{p}=0.016<0.05)$. The difference emerges from the fact that those with $3-5$ years of teaching experience have higher ability to produce alternative solutions than those with less than 2 years of teaching experience $(\mathrm{p}<0.05)$. The ability to produce alternative solutions scores of those with teaching experience over 5 years are higher than those of teachers with teaching experience less than 2 years $(\mathrm{p}<0.05)$. In parallel with our study, Uzümcü and Müezzin (2018) determined statistically significant differences between the ability to produce alternative solutions sub-dimension and the teaching experience. It was observed that the significant difference was due to the high ability to produce alternative solutions scores of those with higher teaching experience compared to those with lower teaching experience. It was determined that there were statistically significant differences in the cognitive flexibility scores of teachers in terms of teaching experience variable $(\mathrm{F}=4,188 ; \mathrm{p}=0.017<0.05)$. The difference stem from the fact that the cognitive flexibility scores of those with $3-5$ years of teaching experience are higher than the cognitive flexibility scores of those with less than 2 years of teaching experience $(\mathrm{p}<0.05)$. The cognitive flexibility scores of those with teaching experience over 5 years are higher than the cognitive flexibility scores of those with teaching experience of less than 2 years $(\mathrm{p}<0.05)$. Similarly, in the study conducted by Uzümcü and Müezzin (2018) it was determined that there was a statistically significant difference between the teaching experience of teachers and their overall cognitive flexibility levels. It was observed that the significant difference was due to the high cognitive flexibility scores of those with high teaching experience compared to those with lower teaching experience.

It was determined that there was statistically no significant difference between the scores of tendency to control and social appearance anxiety in terms of teaching experience variable ( $p>0.05)$.

It was determined that there was statistically no significant difference among the scores of ability to produce alternative solutions, tendency to control, overall cognitive flexibility, and social appearance anxiety in terms of having an administrative task variable $(\mathrm{p}>0.05)$. It can be considered that this is due to the non-homogeneity of administrative tasks in the sample group.

\section{Conclusion}

According to the results of the analysis, it was determined that there were statistically significant differences between the levels of cognitive flexibility and ability to produce alternative solutions, as well as between cognitive flexibility overall scores and teaching experience variable $(\mathrm{p}<0.05)$; however, no statistically significant difference was determined concerning gender, age, marital status, school type, teaching branch, and having an administrative task $(\mathrm{p}>0.05)$. It was determined that there was a statistically significant difference among the social appearance anxiety scores concerning gender, school type, and teaching branch variables $(p<0.05)$; however, no significant difference was detected concerning age, marital status, teaching experience and having an administrative task variables $(\mathrm{p}>0.05)$. It was determined that there was statistically no significant relationship between the overall cognitive flexibility and social appearance anxiety $(\mathrm{p}>0.05)$.

\section{References}

Alemdăg, S., \& Oncü, E. (2015). Examination of teacher candidates' participation in physical activity and social appearance concerns. International Journal of Science Culture and Sport, 3(3), 287-300.

Aygun, M. (2019). Emotional intelligence and leadership in ice hockey athletes. Ankara: Nobel Publishing.

Cox, K. S. (1980). The effects of second-language study on the cognitive flexibility offreshman university students. Unpublished Doctoral Dissertation, The Ohio State University.

Dennis, J. P., \& Wal, V. J. S. (2010). The cognitive flexibility inventory: Instrument development and estimates of reliability and validity. Cognitive Therapy and Research, 34(3), 241-253.Available at: https://doi.org/10.1007/s10608-009-9276-4.

Doğan, T. (2010). Turkish version of the social appearance anxiety scale (SGKÖ): validity and reliability study. Hacettepe University Faculty of Education Journal, 39(39), 151-159.

Eroğlu, E. (2019). Fundamentals of physical education and sports sciences. Ankara: Academician Publishing House.

Eroğlu., E., \& Ersoy, A. (2019). Examination of physical education and sports school students' learned strength levels according to some variables. International Journal of Multidisciplinary Academic Research, 6(2), 68-75.

Gülüm, I. V., \& Dağ, I. (2012). Adaptation of the repetitive thinking scale and cognitive flexibility inventory into Turkish, validity and reliability. Anatolian Journal of Psychiatry / Anatolian Journal of Psychiatry, 13(3).

Güzeltepe, S. (2017). Investigation of cognitive flexibility levels of public personnel in terms of psychological contract roles is a field research: Bakirköy courthouse. Doctoral Dissertation, Istanbul Aydin University Institute of Social Sciences.

Hart, E. A., Leary, M. R., \& Rejeski, W. J. (1989). Tie measurement of social physique anxiety. Journal of Sport and Exercise Psychology, 11 (1), 94-104.Available at: https://doi.org/10.1123/jsep.11.1.94.

Hart., T. A., Flora, D. B., Palyo, S. A., Fresco, D. M., Holle, C., \& Heimberg, R. G. (2008). Development and examination of the social appearance anxiety scale. Assessment, 15(1), 48-59.Available at: https://doi.org/10.1177/1073191 107306673.

Karasar, N. (2005). Scientific research methods. Ankara: Nobel Publishing.

Kılıçarslan, E. (2006). Comparison of the physical self-perception of physical education teachers and other branches: (Example of Kdz. Ereğli). Master Thesis, Sakarya University, Institute of Social Sciences.

Murathan, T. (2018). Use of information technologies in the sports industry (Vol. 3, pp. 1547-1551). Congress Gaziantep: International Professional and Technical Sciences.

Murathan, T., \& Özdemir, K. (2017). Investigation of the attitudes of physical education teacher candidates toward teaching profession and sense of competence in terms of some cariables. Journal of Education and Learning, 6(4), 229-238.Available at: https://doi.org/10.5539/jel.v6n4p229.

Uğraş, S., \& Güllü, M. (2019). Teachers' views on the adequacy of physical education teaching departments. AnemonMuşAlparslan University Journal of Social Sciences, 7(2), 57-65.

Uzümcü, B., \& Müezzin, E. E. (2018). Investigation of teachers' cognitive flexibility and professional satisfaction. Sakarya University Journal of Education, 8(1), 8-25.Available at: https://doi.org/10.19126/suje.325679. 